УДК 94(47).084.1

DOI: 10.12731/2077-1770-2017-4-78-91

\title{
ОРГАНИЗАЦИЯ РАБОТЫ ОРГАНОВ, СНАБЖАЮЩИХ АРМИЮ ПРОДОВОЛЬСТВИЕМ, В ПЕРИОД ВРЕМЕННОГО ПРАВИТЕЛЬСТВА (НА ПРИМЕРЕ НИЖЕГОРОДСКОЙ ГУБЕРНИИ)
}

\section{Субботина И.А.}

Цель. Целью исследования является рассмотрение на основе архивных материалов и опубликованных источников вопроса организации работы органов, ответственных за снабжение армии продовольствием в условиях Первой мировой войньl, в период деятельности Временного правительства (на примере одной из центральных губерний, Нижегородской) как одного из направлений работы власти, сложившейся после победы Февральской революцчии 1917 г. в России.

Метод или методология проведения работ. Основу исследования образуют анализ и синтез материала, историко-системный метод, а также принципы научной объективности и историзма.

Результаты. Автор характеризует систему работы ответственных лии за снабжение армии продовольствием в период деятельности Временного правительства, делает акиент на обязанностях уполномоченных лич, заключающихся главным образом в выполнении выданных нарядов в срок, что в Нижегородской губернии достигалось не всегда. Рассмотрена и охарактеризована система работы органов, основанная на поручениях и назначениях (при наличии исключений), проанализированы основные документы в деятельности: делопроизводственные бумаги и балансовые счета.

Область применения результатов. Результаты исследования могут быть применены в сфере изучения политической и экономической истории ХХ в. и могут быть использовань при разработке курсов по краеведению. 
Ключевые слова: Временное правительство; Нижегородская губерния; снабжение армии; Губернский комиссар; уполномоченный Министерства.

\section{WORK ORGANIZATION OF AUTORITIES SUPPLYING RATIONS FOR THE ARMY DURING THE PROVISIONAL GOVERNMENT PERIOD (ON THE EXAMPLE OF NIZHNY NOVGOROD PROVINCE)}

\section{Subbotina I.A.}

Purpose. The aim of the study is consideration of work organizanions of autorities responsible for the army raitions supplying in the World War I time during the provisional gorvenment activity(for example in one of the Central regions, Nizhny Novgorod) as one of direction of the autority, established after victory of the Febuary revolution in 1917 in Russia. Consideration based on archival materials and published sourses.

Methodology. The bases of the study are analysis and synthesis of material, historical and systematic methods, as well as the principles of scientific objectivity and historicism.

Results. The author characterizes the process of work organazing of autorities responsible for the army ration supplying in time during the provisional gorvenment activity. The author accents duties of autorized persons mainly incurred in fullfilment of issued orders on time, which was not always achieved in Nizhnii Novgorod province. The work system of autorities based on assigments and appointment (in the presence of exeptions) is considered and characterized. The main documents, such as office papers and balance sheets are analyzied.

Practical implications. The research results can be applied in the study of political and economical history in XX century. The research results also may be used in the development of local history courses.

Keywords: Provisional Government; the province of Nizhni Novgorod; the supply of the army; Provincial Commissioner; the Commissioner of the Ministry. 


\section{Введение}

Тема деятельности органов власти Временного правительства во многих сферах долгое время оставалась мало изученной. При рассмотрении проблем исследуемого периода взгляды историков были обращены главным образом на деятельность большевистской партии, Советов и других общественных организаций разных уровней. Современная историческая наука начинает объективное и детальное изучение деятельности органов власти Временного правительства (в том числе и на местных уровнях), на основе чего можно сделать выводы о плюсах и минусах его политики. Эта картина будет неполной без анализа материалов Нижегородской губернии. Научная новизна исследования состоит в том, что на основе анализа источников проводится изучение процесса организации работы органов, снабжающих армию продовольствием в период Временного правительства (на примере одного из центральных территориальных образований государства, Нижегородской губернии), основные направления их деятельности. Тем самым определена возможность проведения дальнейших аналогичных региональных исследований.

Объектом настоящего исследования являются нижегородские органы, снабжающие армию продовольствием, в период власти Временного правительства.

В обзоре использованной в работе литературы следует упомянуть труды М.Т. Лихачева [1] и И.П. Лейберова [2] как представителей советской школы науки с соответствующей духу времени предвзятостью, и современного исследователя М.В. Оськина [3], который не уделяет пристального внимания Нижегородской губернии.

Целью исследования является рассмотрение на основе архивных материалов и опубликованных источников вопроса организации работы органов, ответственных за снабжение армии продовольствием в Нижегородской губернии. Для достижения поставленной цели необходимо решить задачи: описать органы, ответственных за снабжение армии; определить обязанности и возможности их деятельности; проследить ход делопроизводства. 


\section{Материалы и методы}

Использованные источники представлены следующим образом: опубликованные документы органов власти [4] и материалы архивного хранения. В работе были использованы материалы Центрального архива Нижегородской области, в частности, фондов Уполномоченных Министерством Земледелия лиц в Нижегородской губернии: 2144 - уполномоченный Демидов по закупке хлеба для армии; 843 - Уполномоченный по хранению продуктов для армии Салазкин; 844 - Уполномоченный по заготовке мясного продовольствия для армии в Нижегородской губернии Сазонов; 239 - Уполномоченный Министерства Земледелия Гольцгауэр при Нижегородской Губернской Продовольственной Управе.

В своей работе автор стремится следовать принципам научной объективности и историзма. Ее предмет предопределил выбор историко-системного подхода в качестве основного при изучении вопроса организации работы органов, ответственных за снабжение армии продовольствием, в период деятельности Временного правительства. В исследовании применяются как специально-исторические, так и общенаучные методы: анализ и синтез при изучении материалов архивного хранения.

\section{Результаты и обсуждение}

Первая Мировая война поставила Россию в сложное положение. На алтарь победы были брошены все резервы и возможности государства. Важную роль в деле снабжения армии были призваны сыграть местные органы власти. В целях изучения процесса снабжения армии органами власти Временного правительства автор ставит несколько задач: определить ответственных лиц за процесс снабжения, показать механизм работы, выявить достоинства и недостатки работы в деле заготовок сырья для армии.

Начало организации продовольственного снабжения армии было положено решением Совета министров от 30 июля 1914 г. о прямых государственных закупках хлеба. Отдельная роль отводилась местным организациям. В губерниях назначались уполномоченные лица 
под руководством Главного управления земледелия и государственных имуществ, в дальнейшем - Министерства земледелия. К марту 1917 года система была уже поставлена на прочные рельсы, дело обеспечения армии продовольствием для многих уполномоченных стало понятным и привычным, поскольку многие из них стабильно занимали свои места в течение нескольких лет.

Аппарат уполномоченных по снабжению армии в Нижегородской губернии, по примеру многих других регионов, к 1917 году был укомплектован чиновниками со стажем. Перемена власти в стране не упразднила системы; режим Временного правительства привнес в механизм снабжения армии лишь новые лица губернского и столичного уровней, которым уполномоченные подчинялись. Среди губернских чиновников на первое место вышел Губернский Комиссар (далее по тексту Гуком), осуществлявший на местном уровне контроль за качеством работы всех должностных лиц региона, в том числе и уполномоченных по заготовке и хранению продуктов для армии.

К 1917 году в Нижегородской губернии выполняли свои обязанности следующие уполномоченные по обеспечению армии: уполномоченный Министерства Земледелия по хранению продуктов для армии, Салазкин; уполномоченный Министерства Земледелия по заготовке мясного продовольствия для армии, Сазонов; уполномоченный Министерства Земледелия при Нижегородской Губернской Продовольственной Управе, Гольцгауэр; уполномоченный Министерства Земледелия по заготовкам продовольствия и фуража для армии, Минков; уполномоченный Министерства Земледелия по Средней Волге по закупке мочал, рогож для армии, Сироткин; уполномоченный Министерства Земледелия по закупке хлеба для армии, Демидов [5, с. 160]. Обо всех передвижениях на таких постах в рамках уездов или волостей было необходимо письменно заявить как Губернскому Комиссару, так и главному уполномоченному с тем, чтобы все последующие операции велись без участия снятого. Примером таких докладов является документ, присланный Салазкину, который гласит: «Постановлением Продовольственной Комиссии при Волостной Управе от 11 декабря полномочия по ве- 
дению продовольственного дела в Сормовском Волосном Земстве с гр. Константина Петровича Козак сняты. Сообщая об этом, Волостная Управа просит выданные гражданину Козак...полномочия считать недействительными и дел по продовольствию (особенно денежные) по Сормовскому Земству с ним не вести» [9, л. 365].

К сложностям работы уполномоченного следует отнести необходимость иметь дело с материальными ресурсами. Каждый из них имел текущий счет, идентифицированный кодом, на который перечислялись необходимые средства. При смене личности на посту счет также менял владельца как, например, в случае прихода к власти Гольцгауэра: «Ввиду передачи мною всех дел по мясным заготовкам вновь назначенному Уполномоченному Ф.Ф. Гольцгауэру прошу перевести на него текущий счет за № 43425» [6, л. 79].

Процесс делопроизводства в системе уполномоченных был схож с подобным делом у Комиссаров Временного правительства. Неизменным остается линейный принцип соподчиненности губернских чиновников столичным и уездных губернским начальникам. Несмотря на разделение комплекса заготовительных работ по отраслевому принципу среди нескольких уполномоченных лиц, высокой эффективности в процессе заготовки продуктов в уездах и волостях не достигалось. Даже при самой высокой работоспособности человек не смог бы отследить все нюансы сдачи товара в приемные пункты, учитывая территориальный состав Нижегородской губернии, включавшей в себя 11 уездов (волостей было значительно больше). Кроме того, следует учитывать и большой поток корреспонденции, приходившей на имя уполномоченного. При таком объеме работ единственным решением поставленной задачи могло стать наличие помощников у губернских уполномоченных. Должность помощников у местных снабженцев существовала, более того, они имели доступ и к материальным ценностям, что подтверждается документальным свидетельством: «Настоящим сообщаю, что в случае необходимости можете выдавать Вашим помощникам для закупки мяса авансы до 25000 рублей» [6, л. 243]. Нельзя говорить, что средства, выдаваемые в качестве аванса, не подвергались ревизии, при этом 
имелась оговорка, что «в полученных авансах Ваши помощники отчитываются перед Вами» [6, л. 243].

В рамках рассматриваемого вопроса интересен случай договора подряда-найма на покупку «на комиссионных началах овса, ржи, гречи и гречневой крупы. . .в районе Пьянского Перевоза Княгининского уезда» [14, л. 31], который составили и подписали уполномоченный Министерства Земледелия по закупке хлеба для армии в Нижегородской губернии Д.В. Сироткин и крестьяне села Базина Княгининского уезда Бутурлинской волости: Василий Васильевич Панкратов и заштатный города Пьянского Перевоза того же уезда Танайковской волости Степан Михайлович Киселев. Представленный договор - единичный обнаруженный документ, что придает ему уникальность. Документ составлен на юридической основе, рассматриваются все возможные варианты исполнения и нарушения договора, штрафные санкции, система поощрения. Главной обязанностью Панкратова и Киселева являлась покупка хлеба в течение полугода, при этом они «обязуются в это время в пределах Нижегородской губернии ни для кого другого... покупки хлеба не производить» [14, л. 31]. Договор ставил существенным условие о том, чтобы «покупаемый... хлеб удовлетворял кондициям на их покупку», и Панкратов, и Киселев «несут ответственность за качество хлеба до момента вывозки его из амбаров Уполномоченным» $[14$, л. 31 б. $]$. При всей самостоятельности подрядчики были «обязаны еженедельно сообщать по субботам срочной почтой сведения о количестве всех закупленных за последнюю неделю хлебных продуктов и стоимости их уборки» [14, л. 31об.], что подразумевало увеличение ответственности и точности исполнения порученного им дела. Договор предусматривал случай несвоевременного вывоза закупленного сырья по вине Сироткина, что влекло за собой выплату неустойки в процентном отношении за каждый просроченный день; при всем этом в документе четко говорится, что все приобретения делаются Панкратовым и Киселевым исключительно на собственные средства с последующей компенсацией. Условия сделки были выгодны обеим сторонам, поскольку Сироткин получал своевременную и качественную заготовку хлеба в Княгининском уезде, а крестьяне, подписавшие договор, «комиссионное вознаграждение ... по поручению Уполномоченного... по 
пять (5) копеек с каждого купленного пуда хлеба, каковое вознаграждение уплачивается Панкратову и Киселеву по проверке отчета и по сдаче ими всего хлеба» [14, л. 32]. Оценивая договор, можно отметить высокую степень грамотности составления, довольно современную его структуру, не свойственную времени исследования, предусмотрительность в разделе возможных исходов и результатов, а также четкость ведения финансовых взаимоотношений между подрядчиками и уполномоченным. По иным косвенным свидетельствам можно говорить о том, что договоры с населением о закупке продовольствия для уполномоченных применялись на практике, о чем свидетельствует телеграмма от крестьянина П.А. Матяева, направленная уполномоченному П.А. Демидову. Она повествует об одностороннем разрыве ранее заключенного договора и последующем расчете по проделанным мероприятиям: «Ввиду окончания дел по закупке продуктов и сдаче их по нарядам покорнейше прошу считать договор со мной законченным и от дальнейших закупок освободить вследствие моего отъезда из с. Спасскаго. Закупленные мною продукты сданы полностью... Расчет за комиссию может быть произведен по моем приезде» [15, л. 169].

Наряду с договорной основой передачи полномочий по запасам продовольствия для уполномоченных применялась и практика поручений и назначений. Объектом для передачи поручения могли быть как конкретные лица, так и общественные организации. При этом не всегда обговаривалась процедура оплаты труда или вознаграждения. В качестве примера можно привести доклад, сделанный чиновником Самохваловым П.А. Демидову: «Быковская продовольственная управа приемку хлеба поручает кооперативам. Киреева освободил» [15, л. 227].

Губернские уполномоченные были связующим звеном между населением региона и столичным Министерством Земледелия в деле заготовок продуктов для армии. Связь с вышестоящими органами осуществлялась с помощью телеграфа. Циркуляр от 11 июля, пришедший на имя Салазкина, определял назначение всех грузов и говорил, что «на основании циркулярной телеграммы Министра Земледелия за № 2886, все операции...переданы в ведение Московского Городского Продовольственного Комитета.» На этом основа- 
нии предлагалось «описи отправочным документам, уведомления и всю корреспонденцию, связанную с отправками грузов Городскому Продовольственному Комитету адресовать ему же следующим порядком: Москва, Воскресенская пл., д. Лобачева» [8, л. 32]. Такие инструкции выдавались не случайно, поскольку были факты путаницы в документации не только между чиновниками внутри губернии, но и между уполномоченными разных регионов. На этот счет также имелись указания от Московского Городского Продовольственного Комитета, который просил своих подчиненных, чтобы «все расчеты за отправленные в ваш адрес продукты производились только с Вами, с Уполномоченными же других губерний за продукты, отправленные хотя бы и для Московского Губернского Комитета, но предварительно в Ваш адрес, расчеты будете производить Вы» [9, л. 233]. Несмотря на это, в обязанности уполномоченных входило общение с коллегами из других регионов, что практиковалось: «Пшеничной муки не имеем, обратитесь [с] просьбой [к] Уполномоченному Министерства Салазкину [в] Нижний Новгород, [в] обязанности которого лежит отпуск муки воинским частям, хлеба. [Об] этом телеграфировали Губернпродком Кочергин» [8, л. 35].

Операции, осуществляемые ответственными чиновниками по заготовке продовольствия для армии, подразумевали под собой большое количество делопроизводственной документации, относящейся к ведомству Временного правительства. Циркуляры Министерства Продовольствия предписывали учет всей документации за временной промежуток в год, например, «за третий операционный год (за время с 1 июля 1916 по 30 июня 1917 года включительно)» $[13$, л. 288]. При этом обговаривалось, что «весь операционный год должен быть разбит на два периода: а) с 1 июля по 31 декабря 1916 г. и б) с 1 января 1917 по 30 июня 1917 г. включительно» [13, л. 288]. Циркуляр упрощал составление финансовых отчетов, предписывая заполнение графы «Остаток к концу отчетного года» и «О заготовительной стоимости продуктов с указанием: а) стоимости основной (без накладных расходов), б) тары на пуд или ведро и в) всех прочих кроме тары расходов» [13, л. 289]; кроме того, документ предусматривал количественный учет заготовлен- 
ных товаров, а именно: «продуктов, определяемых весом...в пудах нетто; в отдельных случаях, когда нетто осталось невыясненным... - в брутто. Количество яиц определяется числом ящиков в 1440 шт., количество вина и уксуса - числом ведер» [13, л. 289].

Вопреки предписаниям о необходимости срочной делопроизводственной отчетности, нижегородские снабженцы уже в середине марта были предупреждены о некачественном выполнении своих обязанностей, отмеченном в телеграмме главноуполномоченного Мельникова: «Вопреки циркуляру № 618 наблюдается крайнее запоздание высылки уполномоченными документов, что особенно недопустимо при отправках продуктов в адрес уполномоченных Карпова, Воронцова» [11, л. 218]. Телеграмма предупреждала о необходимости соблюдения предписанных правил и предлагала «срочно выслать все недосланные документы и не запаздывать [с] их отсылкой» [11, л. 218]. Оправданием уполномоченным в неспешности отправки документов мог служить большой объем работ по заготовкам и поставкам продуктов и мануфактуры. В подтверждение этому можно привести график работ в выходные дни, присланный Кулыжным Сазонову: «Прошу приложить все старания, чтобы [в] предстоящие праздники погрузка [и] отправка заготовляемых Вами продуктов отнюдь не сократилась против данных Вам нарядов на март, каковые наряды продлены на апрель» [12, л. 168].

Главной обязанностью уполномоченных министерства было выполнение выданных нарядов в срок. Дело заключалось в покупке продовольствия у населения или каких-либо организаций (например, при приобретении обуви) по установленным ценам и последующей передаче в определенные магазины, подведомственные правительству с тем, чтобы военные учреждения могли отовариваться по накладным. Другим каналом сбыта заготовленного были центральные организации по снабжению армии, либо подобные конторы, находящиеся в других регионах. Путями транспортировки выбирались железная дорога либо пароходство, учитывая географическое положение пункта назначения. Кроме того, являясь городом центральной части России, Нижний Новгород зачастую становился своего рода перевалочным пунктом в системе передачи продуктов из восточных регионов страны в столицу. 
В связи с этим нижегородский порт и железнодорожная станция были обязаны не только принимать и отправлять товары, но и вести большое количество бумаг, которые находились под контролем у уполномоченного, который представлял отчетность в Министерство.

Одним из самых сложных и распространенных видов учета являлись документы балансового типа. Зачастую такие бумаги указывали количество прибывших продуктов с пометками об отправителе (указывался регион, где продукт был приобретен), владельце судна и точные цифры выгруженного сырья. Список обязательно имел под собой подпись ответственного за разгрузку и учитывал также количество полученного продукта нижегородским портом в определенный период [7, лл. 1-7].

Дальнейшая процедура заключалась в выполнении нарядов, данных губернии особоуполномоченным или другими ответственными лицами. В телеграмме, полученной третьего сентября Салазкиным, четко определялись объемы необходимых продуктов с указанием мест назначения: «Прошу выслать мукой сто тысяч; из них [в] Рязанский магазин пятнадцать, [во] Владимирский десять, Костромской пять, Московский семьдесят, остальное рожью [в] Брянское интендантское заведение» [10, л. 12]. Приоритетным направлением была указана Рязань; и содержалась просьба «[о] каждой отправке... телеграфировать указанием станции отправления накладных, дабы... оказать содействие скорейшему продвижению [по] назначению, также телеграфировать, [в] какой срок можно рассчитывать [на] высылку всего этого количества» [10, л. 13]. Нужно отметить, что плановые и фактические цифры нарядов совпадали редко, второй показатель был значительно ниже, тем не менее, задания руководства, выраженные в плановых графах, старались выполнить в максимальном объеме с указанием реальных поставок и соблюдением процедуры отчетности: «28 августа погружено со станции Н. Новгород от уполномоченного Салазкина [в] счет наряда №48155 ржи [в] Вязники, Ковров, Орехово один вагон» [10, л. 20].

Главной причиной неполного выполнения нарядов было отсутствие излишков продовольствия у населения после неурожая 1916 г. В связи с этим в 1917 г. « в мае было заготовлено 56\% зерна от плана, 
в июне - 25, в июле - 46, а в августе - только 28 \%» [1, с. 55]. Другая точка зрения гласит, что Временное правительство не смогло провести такого важнейшего практического мероприятия, каким являлся учет имевшихся хлебных запасов к весне 1917 г. Поэтому «за восемь месяцев пребывания у власти Временным правительством было заготовлено 360 млн. пудов хлеба, на 5 млн. пудов меньше, чем за последние восемь месяцев существования царизма. Заготовки февраля - октября не достигли и половины (48\%) потребности страны» [2, с. 113].

К концу октября 1917 года министерство продовольствия поставило вопрос о передаче дела снабжения армии вновь образованным органам местного самоуправления. 4 ноября 1917 года был издан циркуляр о передаче на местах продовольственных дел волостным земствам, который в течение первой половины ноября был разослан в волости Нижегородской губернии. В связи с этим деятельность низовых органов, снабжавших армию продовольствием в период Временного правительства, прекратилась.

\section{Заключение}

Анализ материалов, посвященных организации снабжения армии в Нижегородской губернии, показывает, что ответственными за это лицами были уполномоченные Временного правительства, отвечавшие за разные направления заготовок, однако общее руководство оставалось за Гукомом. Общая практика работы уполномоченных базировалась на системе поручений и назначений, однако наблюдались случаи и договорной основы; основными документами в деятельности были делопроизводственные бумаги и балансовые счета. Главной обязанностью уполномоченных министерства было выполнение выданных нарядов в срок, однако в связи с отсутствием излишков продовольствия у населения Нижегородской губернии эта задача решалась не всегда.

\section{Список литературы}

1. Лихачев М.Т. Банкротство буржуазного реформизма в России (февраль - октябрь 1917 г). М.: Знание, 1979. 64 с.

2. Лейберов И.П. Революция и хлеб. М.: Мысль, 1990. 222 с. 
3. Оськин М.В. Продовольственный вопрос в России в 1917 году: слабое место новой власти // Научные ведомости Белгородского государственного университета. Серия: История. Политология. 2015. Т. 34. № 7. С. 164-171.

4. Победа Октябрьской социалистической революции в Нижегородской губернии. Сборник документов. Горький, 1957. 602 с.

5. Субботина И.А. Организация и деятельность местных органов власти Временного правительства в Нижегородской губернии: дис. ... канд. ист. наук. Н.Новгород, 2005. 225 с.

6. Центральный Архив Нижегородской области (далее по тексту ГКУ ЦАНО). Ф.239. Оп.1. Д.15.

7. ГКУ ЦАНО. Ф.843. Оп.1744. Д.29. ЛЛ.1-7

8. ГКУ ЦАНО. Ф.843. ОП.1744а. Д.3.

9. ГКУ ЦАНО. Ф.843. ОП. 1744a. Д.4.

10.ГКУ ЦАНО. Ф.843. ОП.1744а. Д.5.

11. ГКУ ЦАНО. Ф.844. Оп.1853а. Д.7.

12. ГКУ ЦАНО. Ф.844. Оп.1853а. Д.8.

13. ГКУ ЦАНО. Ф.844. Оп.1853а. Д.13.

14. ГКУ ЦАНО. Ф.2144. Оп.1742. Д.17.

15. ГКУ ЦАНО. Ф. 2144. ОП. 1742. Д.30.

\section{References}

1. Lihachev M.T. Bankrotstvo burzhuaznogo reformizma v Rossii (fevral'oktyabr' $1917 \mathrm{~g}$ ) [The bankruptcy of bourgeois reformism in Russia (February - October 1917)]. Moscow: Znanie, 1979. 64 p.

2. Lejberov I.P. Revolyuciya i hleb [Revolution and bread].Moskow: Mysl', 1990. $222 \mathrm{p}$.

3. Os'kin M.V. Prodovol'stvennyj vopros v Rossii v 1917 godu: slaboe mesto novoj vlasti [The food question in Russia in 1917: the weak point of the new government]. Bulletin of Belgorod state University. Series: History. Political science. 2015. V. 34. № 7, pp. 164-171.

4. Pobeda Oktjabr'skoj socialisticheskoj revoljucii v Nizhegorodskoj gubernii [The victory of the October Socialist Revolution in the Nizhny Novgorod region. Collection of documents]. Gorky, 1957. 602 p. 
5. Subbotina I.A. Organizacija i dejatel'nost'mestnyh organov vlasti Vremennogo pravitel'stva $v$ Nizhegorodskoj gubernii [The organization and activities of local authorities of the Provisional Government in Nizhny Novgorod province]: Dissertation of PhD degree in history. Nizhny Novgorod, 2005. $225 \mathrm{p}$.

6. Central'nyj Arhiv Nizhegorodskoj oblasti [The Central Archive of the Nizhny Novgorod region, next GKU CANO]. F.239. Op. 1. D.15.

7. GKU CANO. F.843. Op. 1744. D.29

8. GKU CANO. F.843. Op. 1744a. D.3.

9. GKU CANO. F.843. Op. 1744a. D.4.

10. GKU CANO. F.843. Op. 1744a. D.5.

11. GKU CANO. F.844. Op. 1853a. D 7.

12. GKU CANO. F.844. Op. 1853a. D.8.

13. GKU CANO. F.844. Op. 1853a. D.13.

14. GKU CANO. F. 2144. Op.1742. D.17.

15. GKU CANO. F.2144. Op.1742. D.30.

\section{ДАННЫЕ ОБ АВТОРЕ}

Субботина Ирина Александровна, доцент кафедры экономики и управления в машиностроении, кандидат исторических наук Арзамасский политехнический институт (филиал) Нижегородского государственного технического университета ул. Калинина, 19, г. Арзамас, Нижегородская область, 607220 , Российская Федерация subbotina.irina.alex@yandex.ru

\section{DATA ABOUT THE AUTHOR}

Subbotina Irina Alexandrovna, Associate Professor, Department of Economics and Management in Mechanical Engineering, Ph. D. in History Nizhni Novgorod State Technical University (Arzamas Branch) 19, Kalinin Str., Arzamas, Nizhegorodsky region, 607220, Russian Federation subbotina.irina.alex@yandex.ru SPIN-code: 2050-6315

ORCID: 0000-0003-3579-2696 